\title{
Decreased mRNA and protein expression of TWIST1 in myocardial tissue of fetuses with ventricular septal defects
}

\author{
YUTING WANG ${ }^{1 *}$, QIDI WANG ${ }^{2 *}$, CHANGLONG GUO $^{2}$, SHUO WANG $^{1}, \mathrm{YUE} \mathrm{QIU}^{2}, \mathrm{HUI} \mathrm{LI}^{1}$ and $\mathrm{XU} \mathrm{MA}^{2}$ \\ ${ }^{1}$ Department of Obstetrics and Gynecology, Shengjing Hospital of China Medical University, Shenyang, Liaoning 110004; \\ ${ }^{2}$ Department of Genetics, National Research Institute for Family Planning, Beijing 100081, P.R. China
}

Received July 15, 2014; Accepted March 26, 2015

DOI: $10.3892 / \mathrm{mmr} .2015 .3734$

\begin{abstract}
Ventricular septal defect (VSD) is the most common type of congenital heart disease (CHD). The single gene mutations or absences that contribute to VSD development are well established; however, the aim of the present study was to measure gene expression variation between VSDs and normal fetal myocardial tissue. TWISTI, an important tumor biomarker, is a basic helix-loop-helix transcription factor that regulates cell proliferation, migration and differentiation in embryonic development and transformed tumor cells. Although growing evidence demonstrates that TWIST1 participates in a variety of human neoplastic diseases, the role of TWISTI in VSD has remained elusive. Twenty-six VSD fetal myocardial tissue samples and 12 normal samples at matched gestational weeks (22-28 weeks) were included in the present study. Using reverse transcription quantitative polymerase chain reaction (PCR) and real-time PCR, it was demonstrated that TWIST1 mRNA was reduced by almost two-fold in the VSD samples compared with the normal samples. Western blot analysis also revealed that TWIST1 expression was decreased by $\sim$ three-fold $(\mathrm{P}=0.001)$ in the VSD samples compared with that in the normal samples. Of note, five complete ventricular (also called functionally univentricular or single ventricular) septal ageneses were identified among
\end{abstract}

Correspondence to: Professor Hui Li, Department of Obstetrics and Gynecology, Shengjing Hospital of China Medical University, 36 Sanhao, Heping, Shenyang, Liaoning 110004, P.R. China E-mail: lihuisjhospital@163.com

Professor Xu Ma, Department of Genetics, National Research Institute for Family Planning, 12 Dahuisi Road, Haidian, Beijing 100081, P.R. China

E-mail: xumagroup@163.com

*Contributed equally

Key words: ventricular septal defect, basic helix-loop-helix transcription factor, TWIST1, differentially expressed gene, congenital heart disease the specimens. For the five complete ventricular septal agenesis samples, similar results to those for other VSD fetal myocardial tissues were obtained. In conclusion, the results of the present study showed that TWISTI mRNA and protein levels were reduced in VSDs. The present study was the first, to the best of our knowledge, to report that TWISTI is not only a tumor biomarker, but may also be involved in the pathogenesis of VSD.

\section{Introduction}

Congenital heart disease (CHD) is the most prevalent neonatal disorder in humans; it is the leading cause of non-infectious infant mortality and affects 4-10 out of every 1,000 live births (1-3). Ventricular septal defect (VSD) is the most common type of CHD and is present in 30-50\% of all cases of CHD $(2,4,5)$. The pathogenesis of VSD is multifactorial, with genetic and environmental factors having important roles (6-7). Although the embryology and physiology of VSD are widely known, its etiology and underlying molecular mechanism have remained elusive.

TWIST1 belongs to the helix-loop-helix (bHLH) family of transcription factors, is highly conserved and is involved in embryonic development $(8,9)$. An animal experiments showed that primary chicken which had lost TWISTI gene expression presented with impaired endocardial cushion development (10). A study on Twist1-null mice revealed that Twistl is a novel bHLH within the cardiac outflow tract (OFT) development (11). In humans, although growing evidence suggests that TWIST1 is an important tumor biomarker (12-14), little is known about this gene's involvement in human heart development, particularly its implication in VSD.

Based on previous studies, the present study hypothesized that TWIST1 may have an important role in the development of VSD. Mutation or loss of numerous types of single genes have been predicted to result in VSDs (15-18); however, the underlying molecular mechanism by which reduced expression of a certain gene or a transcription factor may cause defects in cardiac septation, particularly VSDs, has remained elusive. The aims of the present study were to determine the differential expression of TWISTI mRNA and protein levels in normal and VSD human fetal heart tissues and correlate any observed changes to the etiology of VSD. 
Table I. Clinical classification of VSD in the subjects.

\begin{tabular}{lll}
\hline Group & \multicolumn{1}{c}{ VSD sub-type of the sample } & \multicolumn{1}{c}{ Sample number } \\
\hline VSD & $\begin{array}{l}\text { Sub-arterial VSD } \\
\text { Perimembranous VSD }\end{array}$ & S188 S1015 S1000 S211 \\
& & M1005 M1014 M900 M1009 M501 M1001 \\
& Muscular VSD & M198 M1012 M197 M204 M1007 M194 \\
& Complete ventricular septal & A1004 A203 A208 A1006 A1002 \\
& agenesis (functionally univentricular) & CV191 CV183 CV189 CV1013 CV1003 \\
Normal & - & \\
& - & N216 N178 N175 N176 N196 N199 N209 \\
\hline
\end{tabular}

VSD, ventricular septal defects.

\section{Materials and methods}

Tissue samples. All fetal myocardial tissues were obtained from the Department of Obstetrics and Gynecology at Shengjing Hospital of China Medical University (Shenyang, China) from October 2011 to June 2013. All subjects with chromosomal disorders, for example 22 q11 deletion syndrome and 21-trisomy syndrome $(19,20)$, were excluded. The 26 VSD specimens were diagnosed prenatally with CHDs using three-dimensional echocardiography. The diagnoses were confirmed by pathological autopsy. Myocardial tissue samples from 12 normal fetuses at 22-28 weeks of gestation were collected during surgery for pregnancy termination due to spontaneous abortion or trauma to the pregnant women. All tissue samples were snap frozen in liquid nitrogen and then stored at $-80^{\circ} \mathrm{C}$ until use in order to exclude any tissue heterogeneity that may affect results. All fetal myocardial tissues (with or without VSD) were sampled using the same protocols. Each pregnant woman or her relatives provided written informed consent; the Ethics Committee of the National Research Institute for Family Planning (Shenyang, China) approved the study. The study protocol followed the principles of the Declaration of Helsinki. The characteristics of the study subjects are shown in Tables I and II.

RNA isolation and cDNA synthesis. The TRIzol reagent (Invitrogen Life Technologies, Carlsbad, CA, USA) was used to extract total RNA from $50 \mathrm{mg}$ heart tissue. A NanoDrop ${ }^{\mathrm{TM}}$ 2000 spectrophotometer (Thermo Fisher Scientific, Waltham, MA, USA) was used to measure the RNA concentration. The 260/280 $\mathrm{nm}$ absorbance ratios of the RNA samples ranged from 1.91 to 2.03 and they were stored at $-80^{\circ} \mathrm{C}$ until use. An aliquot $(2 \mu \mathrm{g})$ of RNA from each sample was reverse transcribed into cDNA using the PrimeScript ${ }^{\mathrm{TM}}$ II 1st strand cDNA Synthesis kit (Takara, Dalian, China) according to the manufacturer's instructions.

Reverse transcription quantitative polymerase chain reaction (RT-qPCR). The Sangon Company (Beijing, China) designed the primers, which were used according to the manufacturer's instructions. Details of the primers are listed in Table III. Taq DNA polymerase, 10X Taq Buffer, desoxyribonucleotide triphosphate mixture and cDNA template that was reverse
Table II. Clinical characteristics of the study population.

Characteristic VSD $(n=26)$ Normal $(n=12)$ Univentricular

\begin{tabular}{lrcc}
\hline Male, n (\%) & $19(73.1)$ & $7(58.3)$ & $5(100)$ \\
Female, n (\%) & $7(26.9)$ & $5(41.7)$ & 0 \\
\hline
\end{tabular}

VSD, ventricular septal defects.

transcribed from a previous reaction (all from Tiangen Biotech, Beijing, China) were used to amplify cDNA (100 ng/l) in vitro. RT-PCR was performed as follows: $94^{\circ} \mathrm{C}$ for $5 \mathrm{~min} ; 35$ cycles of $94^{\circ} \mathrm{C}$ for $30 \mathrm{sec}, 60^{\circ} \mathrm{C}$ for $30 \mathrm{sec}$ and $72^{\circ} \mathrm{C}$ for $45 \mathrm{sec} ; 72^{\circ} \mathrm{C}$ for $10 \mathrm{~min}$ using a Bio-Rad S1000 Thermal Cycler system (Bio-Rad Laboratories, Inc., Hercules, CA, USA). $\beta$-actin was used as an internal standard. PCR products were analyzed by electrophoresis on $2 \%$ agarose gels.

Real-time PCR. Real-time PCR to quantify gene expression was performed using an ABI Prism 7000 Sequence Detection System (Applied Biosystems, Life Technologies, Thermo Fisher Scientific) with SYBR Premix Ex Taq ${ }^{\mathrm{TM}}$ II (Takara). The amplification conditions were: $95^{\circ} \mathrm{C}$ for $30 \mathrm{sec} ; 40$ cycles of $95^{\circ} \mathrm{C}$ for $5 \mathrm{sec}$ and $58^{\circ} \mathrm{C}$ for $34 \mathrm{sec}$. The levels of $\beta$-actin mRNA were used to normalize the expression of the target genes. The $2^{-\Delta \Delta \mathrm{Ct}}$ method was used to compare differences in relative gene expression between the controls and VSD samples. Each measurement was repeated three times. A melting curve of the reaction products yielded a single peak in each experiment.

Western blot analysis. Frozen heart tissues from all samples were lysed in radioimmunoprecipitation buffer (C1053; Applygen Technologies Inc, Beijing, China) together with a protease inhibitor (P1265; Applygen Technologies). Total soluble protein lysates $(80 \mu \mathrm{g})$ were boiled for $10 \mathrm{~min}$ and then subjected to $15 \%$ gradient SDS-PAGE (CW2384; CWBiotech, Beijing, China). After electrophoresis, the semi-dry transfer system (Bio-Rad Laboratories, Inc.) was used to transfer the proteins onto nitrocellulose membranes $(0.45 \mu \mathrm{m}$; Bio-Rad Laboratories, Inc.). After blocking in 5\% non-fat dried 
Table III. Primers used in the present study.

\begin{tabular}{llll}
\hline Gene & Forward primer & Reverse primer & Product length (bp) \\
\hline TWIST1 (human) & 5'-GGAGTCCGCAGTCTTACGAG-3' & 5'-TCTGGAGGACCTGGTAGAGG-3' & 211 \\
$\beta$-actin (human) & 5'-TCGTGCGTGACATTAAGGAG-3' & 5'-ATGCCAGGGTACATGGTGGT-3' & 178 \\
\hline
\end{tabular}

milk (Wondersun, Inc., Harbin, China), the nitrocellulose membranes were incubated with mouse monoclonal anti-Twist 1 (1:500; sc-81417; Santa Cruz Biotechnology, Inc., Dallas, TX, USA) and mouse monoclonal anti- $\beta$-actin (1:2,000; HC201-01; TransGen Biotech, Beijing, China) primary antibodies. After washing in phosphate-buffered saline containing Tween 20 (TBST), the membranes were incubated with goat anti-mouse immunoglobulin $\mathrm{G}$, horseradish peroxidase conjugate $(1: 3,000$; HS201; TransGen Biotech). The membranes were washed again in TBST. The enhanced chemiluminescence detection reagents (CW0049; CWBiotech) were used to visualize the blots. ImageJ software (version 1.4.8; National Institute of Health, Bethesda, MD, USA) was used to quantify the protein levels.

Statistical analysis. Statistical analysis was performed using SPSS (version 13.0; SPSS Inc., Chicago, IL, US) and GraphPad Prism (version 5.0; GraphPad Software Inc., La Jolla, CA, USA). The Mann-Whitney test was used for comparisons between the normal controls and VSD groups. All statistical analyses were two-sided and $\mathrm{P}<0.05$ was considered to indicate a statistically significant difference. Values are expressed as the mean \pm the standard error, typically from two to three independent experiments, each with three replicates.

\section{Results}

Clinical characteristics and evaluation of VSDs. Pregnant women underwent pre-natal screening using three-dimensional echocardiography to judge whether the heart of their fetus may be affected by VSD. A normal image of a fetal four-chambered heart with no VSDs was used as a control (Fig. 1A). The three-dimensional echocardiography diagnosed 26 fetuses with VSD at 22-28 weeks of gestation. The sizes of the defects of the 26 VSDs ranged from $4.6-8 \mathrm{~mm}$. The representative image shown in Fig. 1B had a VSD of $5.5 \mathrm{~mm}$. Pathological autopsy confirmed the diagnosis and gender of the 26 VSD specimens (73.1\% male; $26.9 \%$ female). As shown in Table I, 12 cases had defects of the perimembranous septum, five were muscular VSDs and four were sub-arterial type VSDs. There were five complete ventricular septal ageneses among the specimens. As shown in Table II, all five of these complete ventricular septal ageneses were from male fetuses.

TWIST1 expression in fetal myocardial tissue. RT-PCR was used to examine the expression of TWIST1 mRNA in the myocardial tissues of normal fetuses and those with VSD. Specific primers were designed using the TWISTI gene sequence from GenBank and primer specificity was checked using the basic local alignment search tool (BLAST;
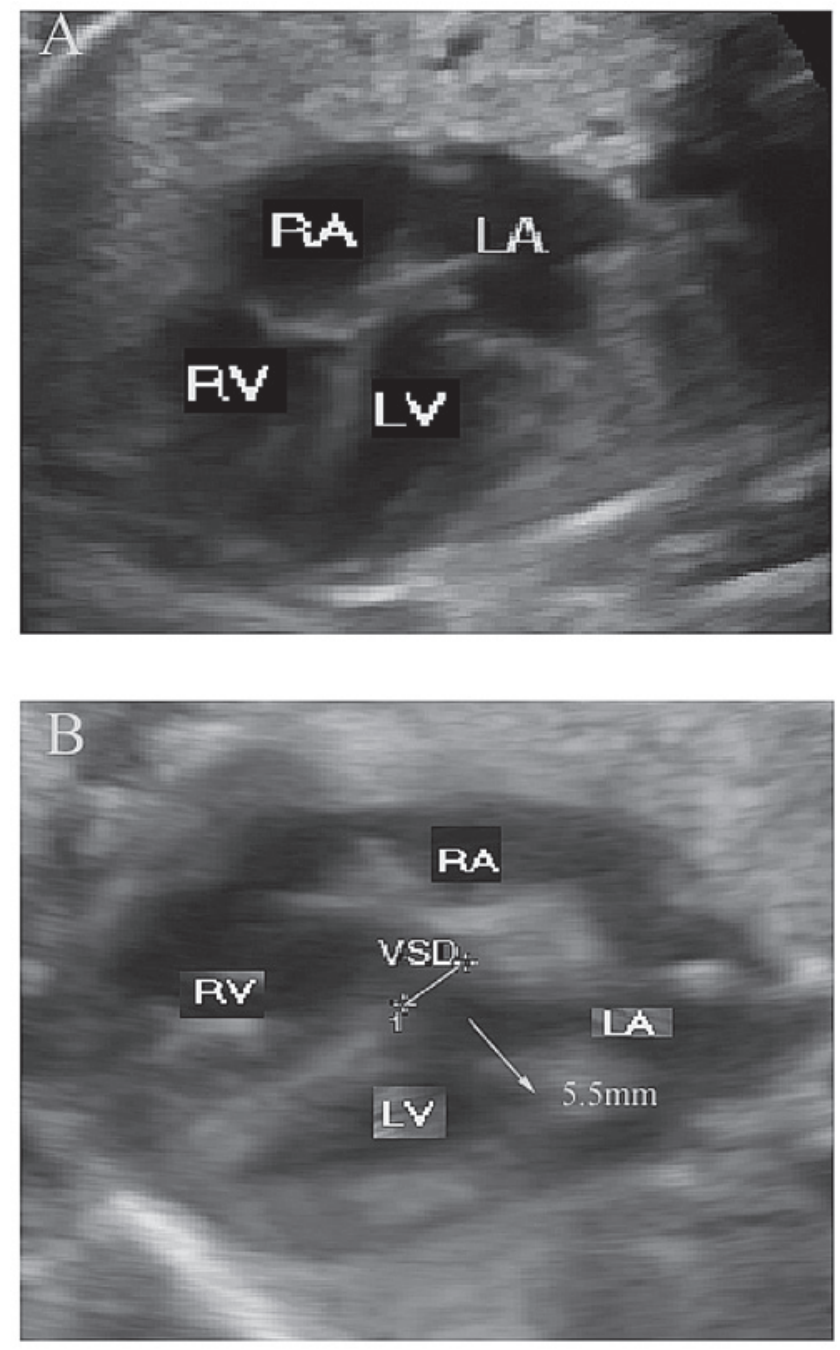

Figure 1. Three-dimensional echocardiographic images of fetal hearts. (A) A normal image of a fetal heart with no VSDs was used as a control. (B) A representative three-dimensional echocardiographic image of 26 cases of VSDs, which shows disruption of the interventricular septum in the four-chamber view. The size of the defect in the heart shown here was $5.5 \mathrm{~mm}$. RA, right atrium; LA, left atrium; RV, right ventricle; LV, left ventricle; VSD, ventricular septal defects.

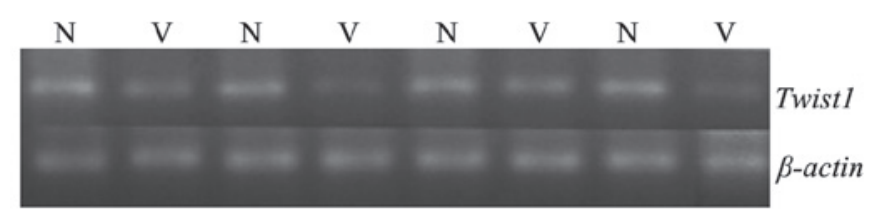

Figure 2. Reverse transcription polymerase chain reaction analysis of TWIST1 expression in human myocardial tissues. $\beta$-actin was used as the internal reference. The products were separated on a $2 \%$ agarose gel, stained with ethidium bromide and visualized under ultraviolet illumination. The lanes marked $\mathrm{N}$ and $\mathrm{V}$ contain the control and ventricular septal defect templates, respectively. 
Table IV. Relative mRNA expression levels of TWIST1 in samples from controls and patients with VSD or univentricular septal angenesis.

\begin{tabular}{lccccr}
\hline Gene & $\begin{array}{c}\text { Control }[\mathrm{RQ} \text { value } \\
\left.\left(2^{-\Delta \Delta \mathrm{Ct}}\right)^{\mathrm{a}}, \mathrm{n}=12\right]\end{array}$ & $\begin{array}{c}\text { VSD [RQ value } \\
\left.\left(2^{-\Delta \Delta \mathrm{Ct}}\right), \mathrm{n}=26\right]\end{array}$ & P-value $^{\mathrm{b}}$ & $\begin{array}{c}\text { Univentricular } \\
{\left[\text { RQ value }\left(2^{-\Delta \Delta \mathrm{Ct}}\right), \mathrm{n}=5\right]}\end{array}$ & P-value $^{\mathrm{c}}$ \\
\hline TWIST1 & $11.04 \pm 2.892$ & $4.738 \pm 0.625$ & 0.010 & $3.675 \pm 1.126$ & 0.039 \\
\hline
\end{tabular}

Values are expressed as the mean \pm standard error. ${ }^{a}$ The RQ values $\left(2^{-\Delta \Delta \mathrm{C} t}\right)$ for control 1 was set as 1 and used for normalization for all samples; ${ }^{\mathrm{b}}$ Mann-Whitney test was performed; $\mathrm{P}<0.01$ vs. control; ${ }^{\mathrm{c}}$ Mann-Whitney test was performed; $\mathrm{P}<0.05$ vs. control. VSD, ventricular septal defects.

Table V. Relative protein levels of TWIST1 in samples from controls and patients with VSD.

\begin{tabular}{lccc}
\hline Gene & Control $(\mathrm{n}=12)$ & VSD $(\mathrm{n}=26)$ & P-value $^{\mathrm{a}}$ \\
\hline TWIST1 & $1.616 \pm 0.261$ & $0.591 \pm 0.078$ & 0.001 \\
\hline
\end{tabular}

Values are expressed as the mean \pm standard error. ${ }^{\mathrm{a}}$ Mann-Whitney test was performed; P-value $<0.01$ vs. control. VSD, ventricular septal defects.

http://blast.ncbi.nlm.nih.gov/Blast.cgi?PROGRAM=blastn\&PAGE_ TYPE=BlastSearch\&LINK_LOC=blasthome). TWISTI mRNA PCR products were not clearly detectable in VSD samples $(n=4)$, but were clearly present in normal fetal heart tissues $(n=4)$ (Fig. 2). Details of the primers are provided in Table III.

TWIST1 mRNA levels are decreased in myocardial tissue of fetuses with VSD. Real-time PCR was used to quantify the relative differences in expression between TWIST1 mRNA in myocardial tissues of normal fetuses and those with VSD. The expression of TWIST1 was two-fold higher in normal tissues compared with that in VSD tissues (Fig. 3). As shown in Table IV, TWIST1 mRNA relative expression levels [RQ $\left(2^{-\Delta \Delta C t}\right)$ values] were significantly lower in fetuses with VSD compared with those from patients with normal fetal myocardial tissues $(\mathrm{P}<0.01)$. For the five complete ventricular septal agenesis samples, similar results were obtained to those for other VSD fetal myocardial tissues $(\mathrm{P}<0.05)$. These results should be further confirmed using an increased number of samples.

TWIST1 protein levels are decreased in myocardial tissue of fetuses with VST. Western blot analysis showed that TWIST1 protein levels were significantly downregulated in the four fetuses with different VSD subtypes compared with those from four selected normal samples (Fig. 4A). To further confirm these results, an in-depth analysis of the peak area of the TWIST1 protein band relative to $\beta$-actin was performed using Image J software for all samples (12 samples without and 26 samples with VSDs) (Fig. 4B). As shown in Table V, the results revealed that TWIST1 expression was decreased by $\sim$ three-fold $(\mathrm{P}=0.001)$ in the VSD samples compared with the normal samples. These data are consistent with the real-time PCR results shown in Fig. 3 and Table IV.

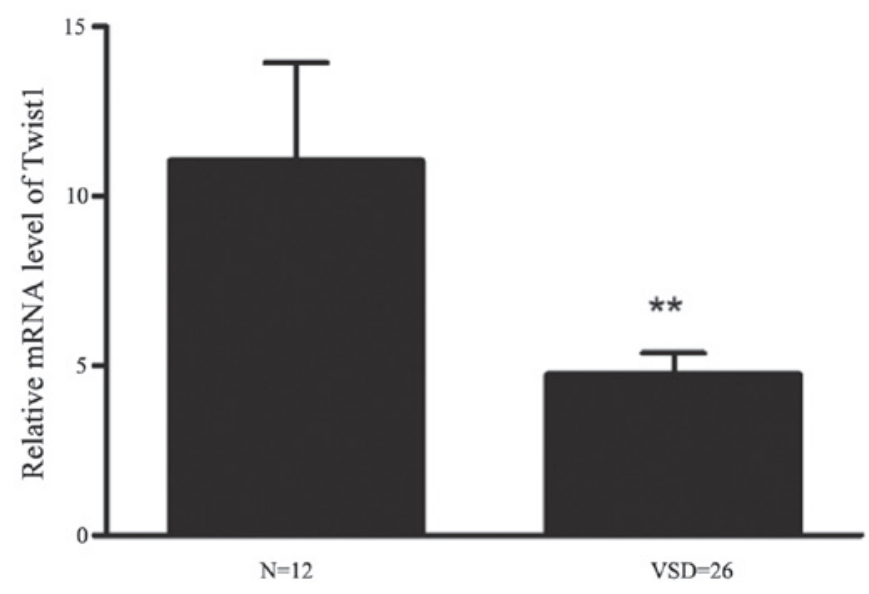

Figure 3. Real-time polymerase chain reaction analysis of TWIST1 gene expression in normal versus VSD samples. TWISTI expression was reduced by 2 -fold in the VSD samples compared with that in normal samples. Values are expressed as the mean \pm standard error for independent cDNA analysis sets normalized to $\beta$-actin expression. ${ }^{* *} \mathrm{P}<0.01$ vs. normal group. VSD, ventricular septal defects.

\section{Discussion}

With the increased incidence of congenital heart disease, neonatal disorders have placed a heavy economic burden on patients and their families, with multiple surgeries required to correct the numerous anatomical defects $(21,22)$. VSDs form a large proportion of CHDs and have attracted increasing attention from researchers (23). VSDs can be classified into four broad categories: Sub-arterial, perimembranous and muscular VSD, as well as complete ventricular septal agenesis (functionally univentricular) (24,25). Of note, it was found that the VSD samples were predominantly from males (73.1\% male; $26.9 \%$ female), particularly in the complete ventricular septal agenesis sub-group (100\% male). This finding is consistent with the observations by Zhao et al (25), who found female predominance in mild CHD [small VSD/patent ductus arteriosus/atrial septal defect (ASD)] and male predominance in severe CHD (large VSD, functionally univentricular heart and tetralogy of Fallot). The results of the present study are in contrast with those of Sands et al (26), who reported that there were significantly more females in the group with VSDs compared with the control group $(\mathrm{P}=0.004)$. This discrepancy is likely caused by the differences in sample selection: Live birth neonates were used by Sands et al (26), while fetal myocardial tissue 

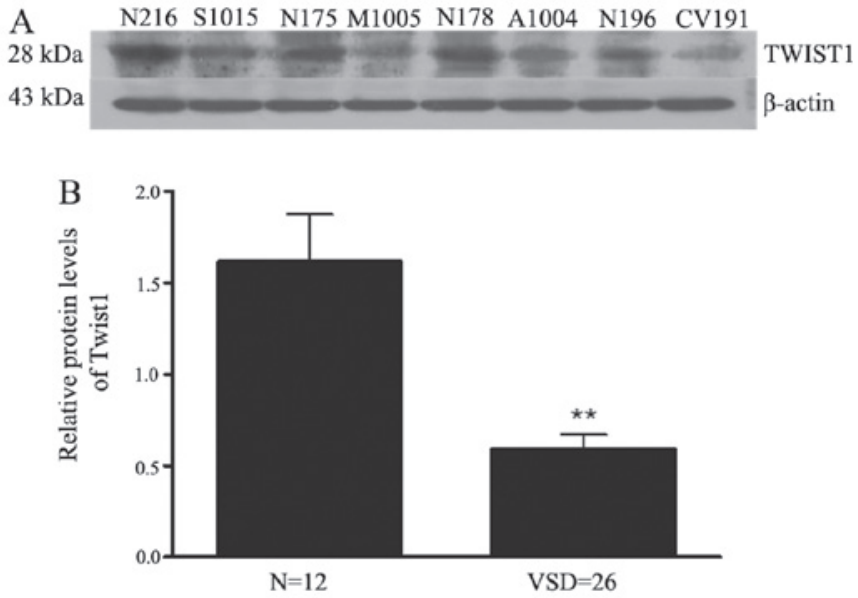

Figure 4. Levels of TWIST1 in human heart tissues as determined by western blot analysis. (A) TWIST1 protein levels were decreased in the four VSD patients compared with those in the four normal samples, which were randomly selected from 38 normal samples; $\beta$-actin was used as the internal reference. Protein molecular size markers are shown on the left in $\mathrm{kDa}$. According to the primary amino acid sequence, TWIST1 was $28 \mathrm{kDa}$ in size. (B) Analysis of the peak area of the TWIST1 protein band relative to $\beta$-actin as assessed using ImageJ software for all samples (12 samples without and 26 samples with VSDs). Western blot analysis for TWIST1 and $\beta$-actin was performed using the same sample on the same membrane. VSD, ventricular septal defects.

with lethal embryonic defects was used in the present study. Thus, males with severe CHDs, including a large VSD or a functionally univentricular heart, would not survive to birth and would be missing from the analysis in the study by Sands et al (26).

Previous studies have shown that TWIST1, as a tumor biomarker, is overexpressed in different types of cancer, including gastric carcinomas (27), breast cancer (28), pancreatic cancer (29), esophageal squamous cell carcinoma (30) and colorectal cancer (31). During embryonic development, TWIST1 has an essential role in specification of the mesoderm and differentiation of the mesoderm-derived tissues. It also regulates morphogenesis in a variety of developing organ systems, including the heart, in animal models (32). In the primary chicken endocardial cushion, Twistl promoted cell proliferation (10). In Twistl (-/-) mice, the cardiac OFT displayed defective maturation and tracking (11). The cardiac OFT and endocardial cushion are important in primordial heart development, suggesting that Twistl is essential for normal heart development. The cardiac cushions separate into the atrioventricular septum; however, a relevant developmental disorder would lead to complete ventricular septal agenesis or subarterial VSD. The cardiac OFT functionally separates the aortic arch and pulmonary trunk; a relevant developmental disorder may result in a perimembranous $\operatorname{VSD}(21,24)$. Previous studies have shown that mice overexpressing TWISTI mutants in cardiomyocytes developed pathological cardiac remodeling, including ASD and VSD, induced by abnormal Akt signaling (enhancement or reduction) (33). TWIST1, also a valve progenitor marker (34), is expressed in newly formed mesenchymal cells of the atrio-ventricular canal and outflow tract and has been shown to have roles in cell self-renewal, proliferation, migration and differentiation $(35,36)$. Persistent TWIST1 expression was shown to increase cell prolifera- tion $(37,38)$; however, decreased expression of TWIST1 may cause VSD.

In the present study, the expression levels of TWIST1 mRNA and protein in fetal myocardial tissue samples were measured using RT-PCR, real-time PCR and western blotting. The results suggested that TWIST1 was not only involved in fetal heart tissue development, but was also downregulated in myocardial cells of fetuses with VSD compared with that in normal fetuses. To the best of our knowledge, the present study was the first to show differences in TWIST1 mRNA as well as protein levels between myocardial tissues of fetuses with VSD and normal samples, suggesting that TWIST1 is a candidate target gene for VSD prevention as well as a prospective marker for VSD.

The strengths of the present study include the strict sample collection process. Data were obtained from freshly frozen cardiac tissue and may be more accurate than those from other studies using cardiac tissue fixed with formalin, which can cause random DNA base damage, thereby affecting PCR fidelity (39). The present study focused on an early time interval of cardiac development, namely embryonic hearts at 22-28 weeks of gestation while the embryo was in utero. This was earlier than the stages examined by other studies on cardiac development of newborns or children and it therefore provided more comprehensive and original information for the study of cardiac development in humans.

Several limitations of the present study should be considered. First, due to the difficulty of obtaining fetal myocardial tissue samples, it was not possible to obtain a sufficient number of complete gestational age-matched samples from fetuses with VSD and healthy controls. Second, it was not possible to obtain heart tissue samples at a variety of developmental stages during pregnancy due to the limitations of pre-natal diagnostic three-dimensional echocardiography techniques. According to previous studies, the earliest time-point at which a diagnosis of congenital heart disease in a fetus can be made is at 14 weeks of gestation; however, the diagnostic specificity is poor (40). Further studies using a larger number of samples are warranted to verify the findings of the present study. In addition, based on the results of the present study obtained from clinical samples, associated in-depth studies will continue to investigate the molecular mechanisms responsible for downregulated gene expression in VSD.

In conclusion, the present study showed that TWISTI gene expression in fetal myocardial tissue was significantly decreased in VSD samples compared with that in normal control subjects. These findings made a significant contribution to the understanding of the development of human VSD and provided novel knowledge regarding the etiology of CHD.

\section{Acknowledgements}

The authors are grateful to Miss. Chaofan Zhang, Miss. Shuang Song, Miss. Weiju Jiang and Mr. Tianchu Huang from the Department of Obstetrics and Gynecology at Shengjing Hospital of China Medical University (Shenyang, China) for collecting the samples. In particular, the authors would like to thank all of the subjects for participating in this study. The present study was supported by the Science and Technology 
Program of Liaoning Province (no. 2011225017) and the Natural Science Foundation of Liaoning province (no. 2014021004).

\section{References}

1. Go AS, Mozaffarian D, Roger VL, et al: Heart disease and stroke statistics-2013 update: a report from the American heart association. Circulation 127: e6-e245, 2013.

2. Hoffman JI: Incidence of congenital heart disease: I. Postnatal incidence. Pediatr Cardiol 16: 103-113, 1995.

3. Hoffman JI and Kaplan S: The incidence of congenital heart disease. J Am Coll Cardiol 39: 1890-1900, 2002.

4. Misra C, Sachan N, McNally CR, et al: Congenital heart disease-causing Gata4 mutation displays functional deficits in vivo. PLoS Genet 8: e1002690, 2012.

5. Xuan C, Jia KG, Wang BB, et al: Identification of two novel mutations of the HOMEZ gene in Chinese patients with isolated ventricular septal defect. Genet Test Mol Biomarkers 17: 390-394, 2013.

6. Jenkins KJ, Correa A, Feinstein JA, et al: Noninherited risk factors and congenital cardiovascular defects: current knowledge: a scientific statement from the American heart association council on cardiovascular disease in the young: endorsed by the American academy of pediatrics. Circulation 115: 2995-3014, 2007.

7. Pierpont ME, Basson CT, Benson DW Jr, et al: Genetic basis for congenital heart defects: current knowledge: a scientific statement from the American heart association congenital cardiac defects committee, council on cardiovascular disease in the young: endorsed by the american academy of pediatrics. Circulation 115: 3015-3038, 2007.

8. Conway SJ, Firulli B and Firulli AB: A bHLH code for cardiac morphogenesis. Pediatr Cardiol 31: 318-324, 2010.

9. Castanon I and Baylies MK: A Twist in fate: evolutionary comparison of Twist structure and function. Gene 287: 11-22, 2002

10. Shelton EL and Yutzey KE: Twist1 function in endocardial cushion cell proliferation, migration and differentiation during heart valve development. Dev Biol 317: 282-295, 2008.

11. Vincentz JW, Barnes RM, Rodgers R, Firulli BA, Conway SJ and Firulli AB: An absence of Twist1 results in aberrant cardiac neural crest morphogenesis. Dev Biol 320: 131-139, 2008.

12. Wang X, Ling MT, Guan XY, et al: Identification of a novel function of TWIST, a bHLH protein, in the development of acquired taxol resistance in human cancer cells. Oncogene 23: 474-482, 2004.

13. Yang J, Mani SA, Donaher JL, et al: Twist, a master regulator of morphogenesis, plays an essential role in tumor metastasis. Cell 117: 927-939, 2004.

14. Yang J, Mani SA and Weinberg RA: Exploring a new twist on tumor metastasis. Cancer Res 66: 4549-4552, 2006.

15. Rajagopal SK, Ma Q, Obler D, et al: Spectrum of heart disease associated with murine and human GATA4 mutation. J Mol Cell Cardiol 43: 677-685, 2007.

16. Garg V: Insights into the genetic basis of congenital heart disease. Cell Mol Life Sci 63: 1141-1148, 2006.

17. Mori AD and Bruneau BG: TBX5 mutations and congenital heart disease: Holt-Oram syndrome revealed. Curr Opin Cardiol 19: 211-215, 2004.

18. Biben C, Weber R, Kesteven S, et al: Cardiac septal and valvular dysmorphogenesis in mice heterozygous for mutations in the homeobox gene Nkx2-5. Circ Res 87: 888-895, 2000.

19. Huber J, Peres VC, de Castro AL, et al: Molecular screening for 22Q11.2 deletion syndrome in patients with congenital heart disease. Pediatr Cardiol 35: 1356-1362, 2014.

20. Tan M, Xu C, Sim SK, Seow AL, Tan TH and Quek SC: Types and distribution of congenital heart defects associated with trisomy 21 in Singapore. J Paediatr Child Health 49: 223-227, 2013.
21. Bruneau BG: The developmental genetics of congenital heart disease. Nature 451: 943-948, 2008.

22. Verheugt CL, Uiterwaal CS, van der Velde ET, et al: The emerging burden of hospital admissions of adults with congenital heart disease. Heart 96: 872-878, 2010.

23. Zhu C, Yu ZB, Chen XH, et al: Screening for differential methylation status in fetal myocardial tissue samples with ventricular septal defects by promoter methylation microarrays. Mol Med Rep 4: 137-143, 2011.

24. Soto B, Becker AE, Moulaert AJ, Lie JT and Anderson RH: Classification of ventricular septal defects. Br Heart J 43: 332-343, 1980.

25. Zhao QM, Ma XJ, Jia B and Huang GY: Prevalence of congenital heart disease at live birth: an accurate assessment by echocardiographic screening. Acta Paediatr 102: 397-402, 2013.

26. Sands AJ, Casey FA, Craig BG, Dornan JC, Rogers J and Mulholland HC: Incidence and risk factors for ventricular septal defect in 'low risk' neonates. Arch Dis Child Fetal Neonatal Ed 81: F61-F63, 1999.

27. Yang Z, Li XJ, Luo T and Wu XT: Expression of TWIST in gastric carcinoma and its correlation with clinical significance. Sichuan Da Xue Xue Bao Yi Xue Ban 42: 625-629, 2011 (In Chinese).

28. Gort EH, Suijkerbuijk KP, Roothaan SM, et al: Methylation of the TWIST1 promoter, TWIST1 mRNA levels and immunohistochemical expression of TWIST1 in breast cancer. Cancer Epidemiol Biomarkers Prev 17: 3325-3330, 2008.

29. Ohuchida K, Mizumoto K, Ohhashi S, et al: Twist, a novel oncogene, is upregulated in pancreatic cancer: clinical implication of Twist expression in pancreatic juice. Int J Cancer 120: 1634-1640, 2007.

30. Yuen HF, Chan YP, Wong ML, et al: Upregulation of Twist in oesophageal squamous cell carcinoma is associated with neoplastic transformation and distant metastasis. J Clin Pathol 60: 510-514, 2007.

31. Valdés-Mora F, Gómez del Pulgar T, Bandrés E, et al: TWIST1 overexpression is associated with nodal invasion and male sex in primary colorectal cancer. Ann Surg Oncol 16: 78-87, 2009.

32. Barnes RM and Firulli AB: A twist of insight-the role of Twist-family bHLH factors in development. Int J Dev Biol 53: 909-924, 2009

33. Lu S, Nie J, Luan Q, et al: Phosphorylation of the Twist1-family basic helix-loop-helix transcription factors is involved in pathological cardiac remodeling. PLoS One 6: e19251, 2011.

34. Wirrig EE and Yutzey KE: Conserved transcriptional regulatory mechanisms in aortic valve development and disease. Arterioscler Thromb Vasc Biol 34: 737-741, 2014.

35. Vrljicak P, Cullum R, Xu E, et al: Twist1 transcriptional targets in the developing atrio-ventricular canal of the mouse. PLoS One 7: e40815, 2012

36. Lee MP and Yutzey KE: Twist1 directly regulates genes that promote cell proliferation and migration in developing heart valves. PLoS One 6: e29758, 2011.

37. Chakraborty S, Wirrig EE, Hinton RB, Merrill WH, Spicer DB and Yutzey KE: Twist 1 promotes heart valve cell proliferation and extracellular matrix gene expression during development in vivo and is expressed in human diseased aortic valves. Dev Biol 347: 167-179, 2010

38. Firulli BA, McConville DP, Byers JS III, Vincentz JW, Barnes RM and Firulli AB: Analysis of a Hand1 hypomorphic allele reveals a critical threshold for embryonic viability. Dev Dyn 239: 2748-2760, 2010.

39. Quach N, Goodman MF and Shibata D: In vitro mutation artifacts after formalin fixation and error prone translesion synthesis during PCR. BMC Clin Pathol 4: 1, 2004.

40. Johnson B and Simpson LL: Screening for congenital heart disease: a move toward earlier echocardiography. Am J Perinatol 24: 449-456, 2007. 